\title{
Post-cardiac injury syndrome
}

\author{
Maria Jaworska-Wilczyńska ${ }^{1}$, Mariusz Kuśmierczyk ${ }^{2}$, Elżbieta Abramczuk ${ }^{1}$, Tomasz Hryniewiecki ${ }^{1}$ \\ ${ }^{1}$ Department of Congenital Cardiac Defects, Institute of Cardiology, Warsaw \\ ${ }^{2}$ Department of Cardiosurgery and Transplantology, Institute of Cardiology, Warsaw \\ Kardiochirurgia i Torakochirurgia Polska 2013; 10 (1): 20-26
}

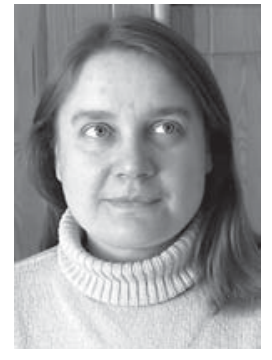

\begin{abstract}
Post-cardiac injury syndrome (PCIS), also known as post-pericardiotomy syndrome, post-myocardial infarction syndrome, or post-commissurotomy syndrome, is a common complication after cardiac surgery, affecting approximately $40 \%$ of patients. PCIS occurs several days to several months after the surgical procedure. The syndrome manifests itself as exudative pericardial or pleural effusion with low-grade temperature and elevated inflammatory parameters. It is generally a self-limiting disease with a favorable prognosis, but it can have a relapsing course and be accompanied by life-threatening complications including cardiac tamponade and constrictive pericarditis.

Key words: post-cardiac injury syndrome, pericarditis, cardiac tamponade, pleuritis.
\end{abstract}

\section{Introduction}

Post-cardiac injury syndrome (PCIS) was first described in the 1950s by William Dressler, a patient suffering from myocardial infarction, in [1].

Similar symptoms were described after cardiac surgery procedures such as valve replacement, congenital heart defects correction, and coronary artery bypass grafting, after cardiac injuries, pulmonary embolism, percutaneous coronary interventions, artificial pacemaker implantation, RF ablation treatment for arrhythmia, as well as after thoracic surgery involving the pericardium (e.g. pulmonary carcino$\mathrm{ma}$ ), even if the cardiac muscle is not damaged - the socalled post-thoracotomy syndrome [2].

\section{General characteristics of post-cardiac injury syndrome}

Post-cardiac injury syndrome (PCIS) is an exudative pericarditis and/or pleuritis related to previous surgical treatment or thoracic injury, but also to myocardial necro-

\section{Streszczenie}

Zespół pourazowy serca (zespół po perikardiotomii, zespół pozawałowy Dresslera, zespół po komisurotomii) to jedno z częstszych powikłań po operacjach kardiochirurgicznych. Dotyczy ok. 40\% pacjentów. Zespół charakteryzuje się pogorszeniem samopoczucia, gorączką lub stanami podgorączkowymi, zapaleniem osierdzia i opłucnych oraz podwyższonymi parametrami zapalnymi. Dolegliwości pojawiają się po kilku dniach lub nawet kilku miesiącach od zabiegu. Rokowanie u chorych z zespołem pourazowym serca jest dobre, choć zwykle przedłuża on hospitalizację, może mieć przebieg nawrotowy oraz może powodować groźne powikłania, szczególnie tamponadę serca i zaciskające zapalenie osierdzia.

Słowa kluczowe: zespół pourazowy serca, zapalenie osierdzia, tamponada serca, zapalenie opłucnej.

sis. The nomenclature is not uniform. Post-cardiac injury syndrome includes:

- post-pericardiotomy syndrome (PPS), occurring after cardiac surgery procedures, more frequently after valve replacement (10-40\% of patients) [3],

- post-myocardial infarction syndrome (PMIS), or Dressler's syndrome with incidence estimated below 5\%, which exhibits a tendency for gradual reduction due to widespread, aggressive, and efficacious treatment of acute coronary syndromes $[1,4]$,

- post-commissurotomy syndrome (PCS) [1],

- post-thoracotomy syndrome (PS) [2].

The syndrome is more frequently associated with younger age groups (age $47 \pm 20$ on average) [4, 5]. It occurs within a period of several days to several months after an operation or myocardial infarction. Although subfebrile temperature may occur in the period preceding the occurrence of the syndrome, the postoperative course may also be uncomplicated. 
Diagnosing the syndrome is based on clinical evaluation; there are no specific tests enabling diagnosis [2].

PCIS is most often characterized by a mild disease course with slight fever (in $66 \%$ of patients), adynamia, and musculoskeletal pain. The dominant symptom is chest pain related to pleuritis and pericarditis (91\%) [1]. The pain is acute and stabbing, and it increases during deep breathing or swallowing, as well as when lying supine. It is most often located in the left part of the chest, less frequently in the substernal area (pericarditis), or in a limited area at the side of the inflamed pleura. The pain decreases when sitting. It can radiate to the spine of scapula, into which the trapezius muscle is inserted, as well as to the neck, arms, and left shoulder; this necessitates differentiation from myocardial ischemia. Approximately $57 \%$ of patients suffer from dyspnea [1]. Concomitant cough or hiccups are less frequently observed [6].

Physical examination shows signs of inflammation with a to-and-fro sound proceeding from the pericardium (in approximately $1 / 3$ of patients) [2]. The sound is most audible in the final phase of exhalation, near the lower left edge of the sternum, as the patient is leaning forward. The dynamics of the auscultative phenomena are distinctive, and involve the disappearance and reappearance of the sounds after intervals lasting from several hours to several days. If effusion is present, the heart sound becomes dampened. Signs of pleural inflammation are relatively frequent $(83 \%$ of patients) [1]: the absence of breath sounds (due to fluid accumulation), crackles associated with inflammatory concentrations in one or both lungs, or pericardial to-and-fro sounds related to the respiratory cycle.

Laboratory examinations reveal the elevation of erythrocyte sedimentation rate (ESR) and C-reactive protein (CRP) inflammation markers in more than $2 / 3$ of patients, as well as slight leukocytosis (49\%) and eosinophilia [1, 7]. These parameters, however, are non-specific, have low prognostic value, and only slightly influence the subsequent therapeutic strategy.

Elevated CRP concentration may, in turn, be used for monitoring the efficacy of the treatment and making the decision to discontinue the therapy [8].

Labeling the cardiac markers is of auxiliary significance. The sometimes elevated concentration of troponin I (in c. 15$49 \%$ of patients) and CK-MB (in 57\%) during pericarditis does not affect the prognosis. Troponin normalizes after 1-2 weeks [9-11]. In patients with pericardial diseases, slight elevation of NT-proBNP concentration, correlating with increased left atrial systolic and diastolic dysfunction, has been described [12]. Some patients exhibited elevated titers of autoantibodies against actin, myosin, troponin I and T, tropomyosin, sarcolemma, endothelium, and anti-nuclear antibodies [1, 2]. These changes currently have only auxiliary significance, and their routine labeling is not recommended.

The presence of pericarditis may be verified by echocardiography, which is the primary diagnostic tool in postcardiac injury syndrome $[2,13]$. It enables the diagnosis of pericardial and pleural effusion, the estimation of the ef- fusion's size, and the determination of its location and hemodynamic significance. It also plays an important role in monitoring the treatment and diagnosing the complications of post-cardiac injury syndrome.

In practice, it is important to establish the location where the fluid layer is thickest (including in regard to localized effusion). According to Weitzman's classification [14], effusion can be categorized as large (in the presence of $>20 \mathrm{~mm}$ of fluid), moderate (10-20 mm), or small (<10 mm). Small effusion is most common in PCIS $-80 \%$ of patients.

It is necessary to conduct echocardiographic evaluation of the potential pressure on the pericardial cavity (cardiac tamponade), pericardial thickness, and signs of constriction (constrictive pericarditis).

Ultrasound examination may also help to establish the puncture site in the serous cavities if a large quantity of fluid is present. It facilitates the differentiation between the causes of thoracic pain and dyspnea.

ECG changes are rare. In the initial phase, concave STsegment elevation and horizontal PR-segment depression opposite to $\mathrm{P}$ wave deflection can be observed (stage I). After several days, the normalization of the repolarization phase occurs, but the PR-segment depression persists (stage II). After subsequent follow-up days, the T waves are inverted (stage III), and, ultimately, the electrocardiogram is normalized back to the state prior to pericarditis (stage IV) - classification according to David Spodick [15]. Q wave development and $\mathrm{R}$ wave regression do not occur.

At times, the only change in the ECG record is the depression of the PR segment. In some patients, the negative $T$ waves and PR depression may persist for many weeks or months after the successful treatment of pericarditis. These changes, however, have no prognostic value and do not influence the risk of inflammation recurrence [15].

In case of large effusion, electrical alternation and sinus tachycardia may be present, with low T wave and QRS complex amplitude [15].

Inflammatory lesions can be confirmed by chest X-ray examination in $79 \%$ of patients [16]. They most often consist of pleural fluid and/or an enlarged cardiac silhouette in c. $28 \%$ of patients, when more than $250 \mathrm{ml}$ of fluid is accumulated in the pericardium [17]. Radiological symptoms may occur up to 2 days before, during, or after the occurrence of subjective symptoms [16].

Additional imaging by means of computed tomography (CT) or nuclear magnetic resonance (NMR) of the chest is recommended in the case of non-diagnostic results of transthoracic echocardiography.

Both forms of examination are very sensitive in terms of detecting localized or generalized effusion. They are useful for measuring the thickness of pericardial and pleural laminae and detecting their calcification. Determining that the cardiac muscle is inflamed through NMR examination may also be of help [10].

If therapeutic para- or pleurocentesis is required, general examination of the obtained fluid should be conducted. In the case of post-pericardiotomy syndrome, the fluid 
is exudative in nature [18]: total protein > $30 \mathrm{~g} / \mathrm{l}$; specific weight > 1016 g/l; LDH activity > $200 \mathrm{U} /$ /; fluid LDH activity/ serum ratio $>0.6$; fluid protein/serum ratio $>0.5$.

\section{Post-cardiac injury syndrome complications Cardiac tamponade}

Cardiac tamponade is a rare, life-threatening complication. It occurs in C. $1-2 \%$ of PCIS patients $[2,19]$. It may be the first symptom of post-cardiac injury syndrome development.

Cardiac tamponade is an impairment of heart function due to an increase in intrapericardial pressure resulting from the accumulation of large amounts of fluid. The hemodynamic effect is related to the impaired filling of the heart cavities, resulting from obstructed venous return, the increase of atrial end-diastolic pressure, and the consequent low output syndrome. The volume of the pericardial fluid, which is responsible for the tamponade, depends on the rate at which the effusion accumulates, as well as on the stiffness and thickness of the pericardial laminae. Acute tamponade may lead to cardiogenic shock $[6,10]$.

The patient suffers from discomfort in the chest, dyspnea (increasing in the recumbent position and during physical exertion), significant and increasing exercise intolerance; syncope or dizziness may occur as well. Localized pressure may result in dysphagia, cough or hoarseness (compression of the recurrent laryngeal nerve), hiccups (phrenic nerve), or nausea (pressure on the diaphragm) [6].

Severe general condition and the necessity to maintain the sitting position are apparent during physical examination. Heart sound is quiet, and the following symptoms occur: tachycardia, increased neck vein distention, hepatojugular reflux, paradoxical pulse (a late, but very sensitive symptom manifested as an excessive decrease in systolic arterial pressure during inhalation by more than $10 \mathrm{~mm} \mathrm{Hg}$ in comparison to the pressure during exhalation), and hypotension (Beck's triad: hypotension, muffled heart sounds, distended neck veins) $[6,10]$.

Echocardiographic examination allows for quick diagnosis (class I recommendation by the ESC 2004) and enables the estimation of pericardial fluid amount and location. Large effusion may produce the picture of a "swinging heart". Cardiac tamponade is characterized by the late diastolic collapse of the right atrial free wall and/or early diastolic collapse of the right ventricular wall. Its late symptom is the diastolic collapse of the left atrial wall or the left ventricle. Paradoxical pulse manifests itself in the echocardiography by increased respiratory variation of the transvalvular blood flow: a drop in blood flow through the mitral and aortic valve during inhalation by over $25 \%$, with a concurrent increase of flow through the tricuspid valve and the pulmonary artery by more than $50 \%$. The distention and the lack of respiratory collapsibility of the inferior vena cava during inhalation indicate elevated pressure in the right atrium and, indirectly, in the pericardial cavity $[10,20]$.

Radiological examination of the chest may reveal an enlarged heart silhouette and show a "water-bottle" or conical shape of the heart. The lung fields remain clear, without stasis. The chest X-ray may also be normal during the course of acute tamponade [20].

If the ECG image is ambiguous, CT or NMR is of auxiliary significance for fluid type differentiation, in cases of encysted fluid, or atypical disease course [10].

Cardiac tamponade is an indication for urgent pericardiocentesis. Employing positive inotropic agents with or without vasodilators (e.g. dobutamine) remains controversial due to its low hemodynamic effect on patients with impaired filling of the heart cavities [21-23]. Cautious fluid supplementation is advisable in patients with hypotension, i.e. with systolic pressure below $100 \mathrm{mmHg}$, in order to maintain hemodynamic stability. Quick intravenous administration of $500 \mathrm{ml}$ of fluid (e.g. physiological saline) within 10 minutes is recommended. In approximately 50\% of patients, this increases cardiac ejection and stabilizes the symptoms $[6,10,21]$.

\section{Post-cardiac injury syndrome recurrence}

Post-cardiac injury syndrome recurrence is quite frequent and is estimated at c. $13 \%$ [2]. It results in increased treatment costs, decreased patient comfort, prolonged treatment, and exposure to adverse effects of the employed therapy.

Recurrence may occur as subsequent relapses of the disease separated by periods of full recovery lasting at least 6 weeks (relapsing or recurrent pericarditis) or as continuous, prolonged inflammation (incessant pericarditis) without remission periods or recurring within 6 weeks from discontinuing medication or reducing its dosage [10].

The reason behind the recurrence is not known. Due to the more frequent presence of autoantibodies in patients [24] and the reaction to immunosuppressive treatment, the prevailing opinion is that the pathomechanism behind recurrence is immunological $[2,10]$.

Risk factors for recurrent PCIS course include: treating the first relapse of the disease with corticosteroids, female gender, persistent increased concentration of hs-CRP, and unsuccessful treatment with NSAIDs [2, 6]. For patients who have suffered their first relapse, the risk of subsequent recurrence increases to c. 50\% [25].

\section{Coronary artery bypass graft occlusion}

The occlusion of coronary artery bypass grafts has been described as a PCIS complication in isolated cases [26].

\section{Constrictive pericarditis}

Constrictive pericarditis is a rare PCIS complication described in c. $0.2 \%$ of cases (4.4\% of cases for every 1000 PCIS per year) [27]. Chronic cardiac tamponade and persistent symptoms of right ventricular congestive heart failure are risk factors for the occurrence of constrictive pericarditis [6].

The disease is associated with a loss of elasticity of the pericardial laminae, as well as with their thickening and calcification secondary to prolonged inflammation, which results in diastolic heart failure symptoms with impaired 
filling of the heart cavities. In some cases, constrictive pericarditis develops without the thickening of pericardial laminae (constriction with normal pericardial thickness) $[6,10]$.

Patients exhibit progressive adynamia and exercise intolerance, dyspnea, dizziness, chest pains, and irregular heart beat (especially during physical exertion). Physical examination demonstrates symptoms of chronic venostasis, with jugular vein distention without vessel wall collapse during inhalation (Kussmaul's sign), with hepatomegaly, positive hepatojugular reflux, circumferential edemas, and fluid presence in the serous cavity [6].

In rare cases, in advanced stages of the disease, auscultative examination reveals an early diastolic heart sound (pericardial knock). Hypotension with low heart rate pressure is a constant symptom. Paradoxical pulse is present in c. $30 \%$ of patients [6].

Hemodynamic disturbances grow along with the progression of systolic dysfunction secondary to myocardial fibrosis and atrophy, or with the occurrence of atrial fibrillation [6].

Laboratory examinations reveal impaired liver function, hypoalbuminemia, signs of enteropathy with protein loss, and proteinuria [6].

The changes in ECG examination are non-specific. They include the presence of a pathological Q wave, low voltage of the QRS complex, flattening or inversion of the T waves, intraventricular conduction defect and atrial arrhythmias (most often atrial fibrillation) $[6,10]$.

The cardiac silhouette may not be enlarged in radiological examination. In about $20 \%$ of patients, calcifications are also present in the pericardium. Moreover, it is possible to observe the dilation of the superior vena cava and the left atrium. Fluid is also frequently present in both pleural cavities [6].

The thickening of the pericardial laminae is rarely visible during transthoracic echocardiographic examination (TTE). Transesophageal echo may be of auxiliary significance. Furthermore, TTE may reveal atrial enlargement (with the size of the ventricles remaining normal), rigid dilation of the inferior vena cava and reverse flow through the dilated hepatic veins during exhalation. Respiratory variation of cardiac blood flow, resulting from the "independence" of the pressure in the pericardial sac from the pressure changes in the thorax, is a characteristic symptom. During inhalation, the blood flow through the pulmonary veins decreases, which leads to a decrease in the inflow of blood to the left atrium, with the filling of the right atrium remaining normal. This leads to the enlargement of the right cavities of the heart and leftward displacement of the interventricular septum. The situation is reversed during exhalation. The main symptoms of pericardial constriction are: restrictive inflow pattern, respiratory variation of the inflow through the atrioventricular valves, and respiratory variation of the $D$ wave of the pulmonary vein flow $[10,28,29]$.

PCIS needs to be differentiated from other causes of fever and chest pains after surgery: a) fever associated with infection (especially during infective endocarditis), b) postperfusion syndrome ("40-day postoperative fever") related to cytomegalovirus (CMV) infection: fever 4-6 weeks after surgery with atypical lymphocytosis and elevated concentration of liver enzymes; no traits of pericarditis or pleuritis.

Moreover, it is necessary to exclude acute coronary syndrome, heart insufficiency, and pulmonary embolism.

In order to establish a diagnosis, apart from collecting case history data and performing physical examination, it is necessary to conduct laboratory tests, including ESR and CRP assessment, electrocardiographic examination (ECG), and radiological examination of the chest. Additional tests include cardiac markers, BNP, arterial blood gas, transthoracic echocardiographic examination (TTE) and computed tomography of the chest. If paracentesis is required, fluid analysis, cultures and Papanicolaou test are also necessary.

The risk factors for the occurrence of post-pericardiotomy syndrome are: age, corticosteroid use, previous pericarditis [1, 30], female gender, and pericardiotomy [2].

\section{Pathogenesis of post-cardiac injury syndrome}

The cause of post-cardiac injury syndrome is not entirely known. PCIS may be initiated by damage to the pericardium and the presence of blood in the intrapericardial space, causing the development of an inflammatory response [2] The immunological nature of the condition seems to be confirmed by the delay in the onset of the symptoms in relation to the time of the procedure or myocardial infarction, the sudden improvement after anti-inflammatory treatment and the tendency for recurrence (sometimes related to the discontinuation of corticosteroids), as well as the lack of correlation between PCIS severity and the presence of myocardial injury markers [4]. It is also supposed that the injury leads to the release and presentation of heart antigens, against which various heart tissue-specific and non-organspecific antibodies are produced. Moreover, immune complexes are developed in the pericardium, lungs and pleural cavity (i.e. in the immediate vicinity of the "injury"), which may be responsible for the onset of an inflammatory response and the occurrence of symptoms typical of the syndrome [31]. A correlation has been demonstrated between high antibody titer and the presence of post-pericardiotomy syndrome [4]. The presence of antibodies against actin, myosin, troponin I and T, tropomyosin, sarcolemma, endothelium, and anti-nuclear antibodies (moderately elevated) was found in patients developing PCIS [32]. It was demonstrated that an elevated titer of anti-nuclear antibodies in the preoperative period may be related to longer treatment and more severe course of post-cardiac injury syndrome [4]. On the other hand, an elevated titer of the above-mentioned antibodies was also found in patients after cardiac surgery without PCIS [33]. Apart from that, the pathogenetic importance of these antibodies has not yet been proven, which leaves the discussion about the clinical significance of these observations still open [33].

Theories pointing to an infectious cause, which could be a) viral infection in the operated myocardium, inducing a systemic inflammatory response against the neoantigen constituted by the infected muscle cell, or b) rheumatic fever recurrence, have not been confirmed [4]. 


\section{Treatment}

The treatment of post-pericardiotomy syndrome is based on the use of high doses of non-steroidal anti-inflammatory drugs (NSAIDs) (recommendation class I, evidence level B, according to ESC 2004) [11]. Preparation selection is empirical and depends on the experience of the clinic, positive response of the patient to the previously applied treatment, or the necessity of prolonged antiplatelet therapy [34]. Ibuprofen is the preferred drug with an initial dose of 300-800 mg every 6-8 hours. Acetylsalicylic acid in a dose of $2 \mathrm{~g}$ per day is an alternative for coronary heart disease patients [35].

The high initial dose of NSAIDs should be administered until the normalization of inflammation markers (CRP, ESR), usually for 7-14 days, and then gradually reduced (Table I) [34].

NSAID treatment increases the risk of damage to the mucous membrane of the digestive tract. The factors increasing the probability of mucous membrane damage are the following: age over 60, peptic ulcers or ulcer bleeding, other serious diseases, taking high doses of NSAIDs or several drugs from this group at the same time, glucocorticoid or anticoagulant treatment, and Helicobacter pylori infection [20]. In patients with two or more risk factors, protection of the gastric and duodenal mucosa with the use of protonpump inhibitors or $\mathrm{H} 2$ receptor antagonists is advised [36].

The recommended treatment in the acute phase of pericarditis is rest and reduction of physical effort until the normalization of inflammatory markers and the abatement of effusion in echocardiographic examination. Return to competitive sports is possible after at least 6 months from the previous episode of pericarditis, especially with concomitant myocardial infection [34].

According to the ESC recommendations of 2004, colchicine is of auxiliary significance in treating acute pericarditis (recommendation class Ila, evidence level B). It is recommended to administer $1 \mathrm{mg}$ of the drug on the first day and $1 \mathrm{mg} / 24 \mathrm{~h}$ in two divided doses for 3 months, in monotherapy or with NSAIDs [35, 37, 38]. In patients with body mass below $70 \mathrm{~kg}$, reducing the daily dose by half is advisable.

In the treatment of pericarditis recurrence, colchicine is used optionally to NSAIDs (recommendation class I, evidence level B, according to ESC 2004) [11].

New research concerning the effects of colchicine in doses of $0.5-1 \mathrm{mg} / 24 \mathrm{~h}$ points to the possibility of employing it in primary prophylaxis and preventing disease recurrence [37].

For patients who do not tolerate the therapy or do not show any signs of improvement, it is recommended to use corticosteroids (prednisone - 0.2-0.5 mg/kg per $24 \mathrm{~h}$ with gradual dose reduction by about 5-10 $\mathrm{mg}$ per week) together with NSAIDs or colchicine, or in monotherapy [11]. This is, however, associated with increased recurrence risk of PCIS. Intrapericardial infusions of glucocorticoids are also used [11].

Isolated reports point to positive reactions to methotrexate [39], azathioprine, cyclophosphamide, and large doses of intravenous immunoglobulin (IVIG) [40] in the treatment of refractory syndromes. Pericardiocentesis is performed in the case of cardiac tamponade or large pericardial effusions, present for at least one week despite comprehensive
Tab. I. Empirical anti-inflammatory therapy in pericarditis [35]

\begin{tabular}{lccc} 
Characteristic & Ibuprofen & $\begin{array}{c}\text { Acetylsalicylic } \\
\text { acid }\end{array}$ & Indometacin \\
initial dose & $\begin{array}{l}3 \times 600 \mathrm{mg} \\
2-4 \mathrm{~g} / 24 \mathrm{~h}\end{array}$ & $3 \times 50 \mathrm{mg}$ \\
\hline $\begin{array}{l}\text { maintenance } \\
\text { dose }\end{array}$ & $\begin{array}{c}2 \times 600 \mathrm{mg} \text { or } \\
3 \times 400 \mathrm{mg}\end{array}$ & $1-3 \mathrm{~g} / 24 \mathrm{~h}$ & $75-150 \mathrm{mg} / 24 \mathrm{~h}$ \\
\hline $\begin{array}{l}\text { treatment } \\
\text { duration }\end{array}$ & & $2-4$ weeks \\
\hline monitoring & & $\begin{array}{l}\text { CRP, number } \\
\text { of leukocytes }\end{array}$ \\
\hline $\begin{array}{l}\text { discontinu- } \\
\text { ation }\end{array}$ & $1-2$ weeks & $\begin{array}{l}\text { after normali- } \\
\text { zation of CRP }\end{array}$ \\
\hline
\end{tabular}

CRP - C-reactive protein

treatment (recommendation class la, evidence level B, according to ESC 2004) [11].

Puncture, made via an infrasternal approach using a long needle with a mandrin (Tuohy or thin-walled $18 \mathrm{G}$ ), directed at an angle of 30 degrees towards the left shoulder, is performed with echocardiographic or fluoroscopic control in a hemodynamic laboratory. This approach avoids the coronary arteries, the internal thoracic artery, and the pleural cavity. Aspiration of small amounts of fluid (up to 1 liter) is recommended in order to prevent acute right ventricular dilation (rapid decompression syndrome). The puncture should be performed under close supervision with the control of arterial blood oxygen saturation, arterial pressure, and electrical activity of the heart. Prolonged drainage of the pericardial cavity is taken into consideration in patients with rapid fluid accumulation (over $25 \mathrm{ml} / 24 \mathrm{~h}$ ) [11]. It is performed by means of the Seldinger method, introducing the preferred catheter to the pericardium using a director [41].

Contraindications for pericardiocentesis are the following:

- aortic dissection - absolute contraindication

relative contraindications:

- uncontrolled coagulopathy,

- successful anticoagulant treatment

- thrombocytopenia below 50 000/ $\mathrm{mm}^{3}$,

- small effusion in a location which is difficult to puncture (posterior part).

The possible complications of pericardiocentesis include: rupture and perforation of the heart or the coronary vessels, aeroembolism, pneumothorax, cardiac dysrhythmia (bradycardia resulting from vasovagal response), and puncture of the peritoneum or abdominal organs [20].

Hindered access to the localized fluid pressing on the heart cavities and the severe course of pericarditis related to recurrent cardiac tamponade, which cannot be treated with the standard anti-inflammatory therapy, may sometimes require surgical decompression by means of percutaneous balloon pericardiotomy or surgical drainage with the creation of a pericardial window (recommendation class IIb, evidence level B, according to ESC 2004). Direct drainage of the pericardium is performed via an infrasternal approach [42]. In case of recurrent and prolonged effusions, a connection is made with the pleural 
cavity or the peritoneum [42]. Since the increased reoperation risk in the case of these treatment methods has been described, some centers prefer to perform pericardiectomy by means of minithoracotomy via an anterolateral approach [42].

Surgical treatment is only taken into consideration in cases of very large effusions (both symptomatic and silent) requiring repeated pericardiocenteses, as well as after unsuccessful pericardial therapy. Constrictive pericarditis, after unsuccessful anti-inflammatory treatment applied for at least 6 months and progressive cardiac insufficiency, constitutes another indication for surgical treatment $[6,11$, 42]. Indications and contraindications for pericardiotomy can be found in Table II.

The perioperative mortality rate after pericardiotomy is about $5-10 \%$ [42]. The risk factors include: old age, cardiac insufficiency (NYHA class III/IV), intensified symptoms of right ventricular insufficiency, pulmonary hypertension, left ventricular systolic dysfunction, extensive myocardial fibrosis and atrophy, and kidney and liver function impairment [42]. The most severe complications related to the surgical treatment are acute cardiac insufficiency, bleeding, and cardiorrhexis [6].

Depending on the extent and localization of pericardial lesions, it is possible to consider radical pericardiotomy involving the removal of the anterior, peridiaphragmatic, and posterior parts of the pericardium, while sparing the tissue in the vicinity of the phrenic nerve, or the simpler to perform and less extensive anterior pericardiotomy, which involves removal of the pericardium above the right and left ventricles, sparing the pericardium above the atria. The symptoms of the constriction regress slowly several months or weeks after the surgical treatment. Full normalization of hemodynamic parameters is found in 60\% [6] $84 \%$ [43] of patients.

In case of massive symptomatic effusion in the pleural cavity, taking place in the course of post-cardiotomy syndrome, thoracentesis is recommended. In case of recurring effusion (or pneumatosis after thoracentesis), pleural cavity drainage is advised.

The use of diuretics, especially loop diuretics, is a generally accepted form of treatment in PCIS with effusion in the pleural and/or pericardial cavity. However, the effectiveness and mechanism of their effect on PCIS are still unclear and require further research.

\section{Conclusions}

The post-cardiac injury syndrome includes the postpericardiotomy syndrome, post-myocardial infarction syndrome (Dressler's syndrome) and post-commissurotomy syndrome.

Diagnosis is based on the following clinical criteria: occurrence about 1 week after an operation (injury) or myocardial infarction, accompanied by moderate fever, presence of fluid in the pleural and pericardial cavities, elevated $E S R$, leukocytosis and the presence of fluid in echocardiographic examination and radiological image of the chest.
Tab. II. Indications and contraindications for pericardiotomy [6]

\begin{tabular}{ll} 
Indications & Contraindications \\
decreased exercise tolerance & transient pericarditis \\
\hline $\begin{array}{ll}\text { jugular venous hypertension } \\
\text { (a systemic venous hyper- }\end{array}$ & $\begin{array}{l}\text { early asymptomatic constriction } \\
\text { (NYHA I), with abnormal results of: } \\
\text { - exercise tests with maximum oxy- } \\
\text { gen consumption measurement } \\
\text { • jugular venous pressure measu- } \\
\text { rements } \\
\text { • liver function evaluations }\end{array}$ \\
\hline necessity of diuretic treat- & $\begin{array}{l}\text { extensive myocardial fibrosis or } \\
\text { ment }\end{array}$ \\
\hline liver failure signs & advanced heart failure (NYHA IV) \\
\hline
\end{tabular}

NYHA - New York Heart Association; CT/NMR - computed tomography/nuclear magnetic resonance

The cause of post-cardiac injury syndrome is not entirely known. An autoimmune mechanism with a humoral and cellular response is currently postulated.

The treatment is based on the use of non-steroidal anti-inflammatory drugs (NSAIDs), colchicine and/or corticosteroids.

The prognosis is good in the majority of cases; however, recurrence is still possible.

\section{References}

1. Wessman DE, Stafford CM. The postcardiac injury syndrome: case report and review of the literature. South Med J 2006; 99: 309-314.

2. Imazio M. The post-pericardiotomy syndrome. Curr Opin Pulm Med 2012; 18: 366-374.

3. Miller RH, Horneffer PJ, Gardner TJ, Rykiel MF, Pearson TA. The epidemiology of the postpericardiotomy syndrome: a common complication of cardiac surgery. Am Heart J 1988; 116: 1323-1329.

4. Erlich JF, Paz Z. Postpericardial injury syndrome: an autoimmune phenomenon. Clin Rev Allergy Immunol 2010; 38: 156-158.

5. Köhler I, Saraiva PJ, Wender OB, Zago AJ. Behavior of inflammatory markers of myocardial injury in cardiac surgery: laboratory correlation with the clinical picture of postpericardiotomy syndrome. Arq Bras Cardiol 2003; 81: 279-290.

6. Seferović PM, Ristić AD, Maksimović R, Simeunović DS, Milinković I, Seferović Mitrović JP, Kanjuh V, Pankuweit S, Maisch B. Pericardial syndromes: an update after the ESC guidelines 2004. Heart Fail Rev 2012 [Epub ahead of print].

7. Larson DL. Relation of the postcommissurotomy syndrome to the rheumatic state. Circulation 1957; 15: 203-209.

8. Imazio M, Brucato A, Maestroni S, Cumetti D, Dominelli A, Natale G, Trinchero R. Prevalence of C-reactive protein elevation and time course of normalization in acute pericarditis: implications for the diagnosis, therapy, and prognosis of pericarditis. Circulation 2011; 123: 1092-1097.

9. Agewall S, Giannitsis E, Jernberg T, Katus H. Troponin elevation in coronary vs. non-coronary disease. Eur Heart J 2011; 32: 404-411.

10. Khandaker MH, Espinosa RE, Nishimura RA, Sinak LJ, Hayes SN, Melduni RM, Oh JK. Pericardial disease: diagnosis and management. Mayo Clin Proc 2010; 85: 572-593.

11. Maisch B, Seferović PM, Ristić AD, Erbel R, Rienmüller R, Adler Y, Tomkowski WZ, Thiene G, Yacoub MH; Task Force on the Diagnosis and Management of Pricardial Diseases of the European Society of Cardiology. Guidelines on the diagnosis and management of pericardial diseases executive summary; The Task force on the diagnosis and management of pericardial diseases of the European society of cardiology. Eur Heart J 2004; 25: 587-610.

12. Mady C, Fernandes F, Arteaga E, Ramires FJ, Buck Pde C, Salemi VM, Ianni BM, Nastari L, Dias RR. Serum NT pro-BNP: relation to systolic and diastolic function in cardiomyopathies and pericardiopathies. Arq Bras Cardiol 2008; 91: 46-54.

13. Bucekova E, Simkova I, Hulman M. Postpericardiotomy syndrome - postcardiac injury syndrome. Bratisl Lek Listy 2012; 113: 481-485. 
14. Weitzman LB, Tinker WP, Kronzon I, Cohen ML, Glassman E, Spencer FC. The incidence and natural history of pericardial effusion after cardiac surgery - an echocardiographic study. Circulation 1984; 69: 506-511.

15. Spodick DH. Acute pericarditis: current concepts and practice. JAMA 2003; 289: 1150-1153.

16. Kaminsky ME, Rodan BA, Osborne DR, Chen JT, Sealy WC, Putman CE. Postpericardiotomy syndrome. AJR Am J Roentgenol 1982; 138: 503-508.

17. Troughton RW, Asher CR, Klein AL. Pericarditis. Lancet 2004; 363: 717-727.

18. Stelzner TJ, King TE Jr, Antony VB, Sahn SA. The pleuropulmonary manifestations of the postcardiac injury syndrome. Chest 1983; 84: 383-387.

19. Prince SE, Cunha BA. Postpericardiotomy syndrome. Heart Lung 1997; 26: 165-168.

20. Szczeklik A. Choroby wewnętrzne. Medycyna Praktyczna, Kraków 2005.

21. Spodick DH. Acute cardiac tamponade. N Engl J Med 2003; 349: 684-690.

22. Spodick DH. Acute cardiac tamponade. Am Heart J 1991; 122: 1794.

23. Gascho JA, Martins JB, Marcus ML, Kerber RE. Effects of volume expansion and vasodilators in acute pericardial tamponade. Am J Physiol 1981; 240: $\mathrm{H} 49-\mathrm{H} 53$.

24. Caforio AL, Brucato A, Doria A, Brambilla G, Angelini A, Ghirardello A, Bottaro S, Tona F, Betterle C, Daliento L, Thiene G, lliceto S. Anti-heart and antiintercalated disk autoantibodies: evidence for autoimmunity in idiopathic recurrent acute pericarditis. Heart 2010; 96: 779-784.

25. Imazio M. Pericarditis: pathophysiology, diagnosis, and management. Curr Infect Dis Rep 2011; 13: 308-316.

26. Urschel HC Jr, Razzuk MA, Gardner M. Coronary artery bypass occlusion second to postcardiotomy syndrome. Ann Thorac Surg 1976; 22: 528-531.

27. Imazio M, Brucato A, Maestroni S, Cumetti D, Belli R, Trinchero R, Adler Y. Risk of constrictive pericarditis after acute pericarditis. Circulation 2011; 124: $1270-1275$

28. D'Cruz IA, Dick A, Gross CM, Hand CR, Lalmalani GG. Abnormal left ventric ular-left atrial posterior wall contour: a new two-dimensional echocardiographic sign in constrictive pericarditis. Am Heart J 1989; 118: 128-132.

29. Echokardiografia. Hoffman P, Kasprzak JD (eds.). Via Medica, Gdańsk 2004.

30. Kelly BM, Nicholas JJ, Chhablani R, Kavinsky CJ. The postpericardiotomy syndrome as a cause of pleurisy in rehabilitation patients. Arch Phys Med Rehabil 2000; 81: 517-518.
31. De Scheerder I, Wulfrank D, Van Renterghem L, Sabbe L, Robbrecht D, Clement D, Derom F, Plum J, Verdonk G. Association of anti-heart antibodies and circulating immune complexes in the post-pericardiotomy syndrome. Clin Exp Immunol 1984; 57: 423-428.

32. Wehlou C, Delanghe JR. Detection of antibodies in cardiac autoimmunity. Clin Chim Acta 2009; 408: 114-122.

33. AkI ES, Latif N, Dunn MJ, Rose ML, Yacoub MH. Antiheart antibodies following open heart surgery: incidence and correlation with postpericardiotomy syndrome. Eur J Cardiothorac Surg 1992; 6: 503-507.

34. Imazio M, Brucato A, Trinchero R, Adler Y. Diagnosis and management of pericardial diseases. Nat Rev Cardiol 2009; 6: 743-751.

35. Imazio M, Adler Y. Treatment with aspirin, NSAID, corticosteroids, and colchicine in acute and recurrent pericarditis. Heart Fail Rev 2012. [Epub ahead of print]

36. Tielemans MM, Eikendal T, Jansen JB, van Oijen MG. Identification of NSAID users at risk for gastrointestinal complications: a systematic review of current guidelines and consensus agreements. Drug Saf 2010; 33: 443-453.

37. Imazio M, Cecchi E, Trinchero R; COPPS Investigators. Colchicine for the prevention of the postpericardiotomy syndrome: the COPPS trial. Int J Cardio 2007; 121: 198-199.

38. Eguchi T, Yoshida K, Hamanaka K, Kurai M. Colchicine as an effective treatment for postpericardiotomy syndrome following a lung lobectomy. Interact Cardiovasc Thorac Surg 2010; 11: 869-871.

39. Zucker N, Levitas A, Zalzstein E. Methotrexate in recurrent postpericardiotomy syndrome. Cardiol Young 2003; 13: 206-208.

40. Wendelin G, Fandl A, Beitzke A. High-dose intravenous immunoglobulin in recurrent postpericardiotomy syndrome. Pediatr Cardiol 2008; 29: 463-464.

41. Kardiologia. Pruszczyk P, Hryniewiecki T, Drożdż J (eds.). Wielka Interna. Medical Tribune Polska, Warszawa 2009

42. Cho YH, Schaff HV. Surgery for pericardial disease. Heart Fail Rev 2012 [Epub ahead of print]

43. Ghavidel AA, Gholampour M, Kyavar M, Mirmesdagh Y, Tabatabaie MB. Constrictive pericarditis treated by surgery. Tex Heart Inst J 2012; 39: 199-205. 